\title{
NONADDITIVE EFFECTS OF TERRESTRIAL AND AQUATIC PREDATORS ON JUVENILE ESTUARINE FISH
}

\author{
Larry B. Crowder, ${ }^{1}$ Deborah D. Squires, ${ }^{2}$ and James A. Rice ${ }^{2}$ \\ ${ }^{1}$ Nicholas School of the Environment and Department of Zoology Duke University Marine Laboratory, \\ Beaufort, North Carolina 28516 USA \\ ${ }^{2}$ Department of Zoology North Carolina State University Raleigh, North Carolina 27695 USA
}

\begin{abstract}
Small fish frequently avoid large fish predators by moving into shallow refuges, but this can increase encounters with terrestrial piscivores. In previous experiments, we documented that juvenile spot (Leiostomus xanthurus) respond to southern flounder (Paralichthys lethostigma) by moving into shallow water. This might increase their risk of predation by birds. We conducted a pond-scale field experiment to test the hypothesis that predation by birds and flounder will have nonadditive effects on spot survival and size. We expected spot to have lower survival in the presence of both predators than expected based on their additive effects (i.e., facilitation among predators). The experiment was a $2 \times 2$ factorial with and without flounders and bird access. Flounder significantly reduced spot survival while birds did not, but there was a significant interaction effect. Spot survived better with both predators than expected based on adding separate predator effects. Mean spot growth rate was unaffected by treatment. Spot moved to shallow water in the presence of flounder and aggregated more tightly in the presence of birds. The observed nonadditive effects could have been due to interference between flounder and birds. However, because all the flounder in our experiments survived and their growth was unaffected by birds, we favor the idea that behavioral changes (increased aggregation) by spot to avoid bird predation also further reduced their vulnerability to flounder. Our results suggest that modeling the effects of multiple predators will be more complicated than simply adding up the effects observed in experiments with single predators.
\end{abstract}

Key words: estuarine fish; Leiostomus xanthurus; nonadditive behavioral effects; Paralichthys lethostigma; piscivorous birds; predation risk and responses.

\section{INTRODUCTION}

Predation is an important interaction that structures aquatic communities (Brooks and Dodson 1965, Paine 1966, Addicott 1974, Peckarsky 1980, Peckarsky and Dodson 1980, Morin 1983, Power et al. 1985, Carpenter et al. 1987, Kerfoot and Sih 1987, Wilbur 1987, Power 1990). Predators can have direct effects by imposing higher mortality rates, or indirect effects via food web linkages or behavioral effects (Kerfoot and Sih 1987, Wootton 1993, 1994). Increasing interest in indirect effects was stimulated by a review (Sih et al. 1985) which found that $40 \%$ of predation experiments reported unexpected effects, often increases in the abundance of prey taxa. Many of these indirect effects derive from sublethal behavioral effects on prey habitat use (Werner et al. 1983, Power et al. 1985) and activity levels (Stein and Magnuson 1976, Sih 1982) which Wootton (1993) referred to as interaction modifications. The indirect effects of predation (which can be positive or negative) are now also considered important selection pressures that structure natural communities (Abrams 1987, Sih 1987, Wootton 1994).

Manuscript received 8 March 1996; revised 7 October 1996; accepted 14 November 1996; final version received 2 December 1996.
Indirect effects have been documented for predators on prey (e.g., the keystone predator effect, Paine 1966, Dodson 1974; and cascading trophic interactions, Hurlburt et al. 1972, Carpenter et al. 1985, Power 1990), and among competitors (e.g., indirect mutualism, Levine 1976; and apparent competition, Holt 1977). But little has been reported regarding the consequences of interactions among predators or the implications of these interactions for their prey.

Studies of predator-prey interactions usually consider only one type of predator when evaluating predation effects on prey abundance or behavior (Brooks and Dodson 1965, Zaret 1980, Sih et al. 1985), but most prey face a number of potential predators which use a variety of search and capture strategies. In the past ten years, an increasing number of experimental ecologists have examined the effects of multiple predators on their prey. Examples include effects of different size classes of the same predator species (Rice et al. 1993), interactions among organisms in the same order (stoneflies, Peckarsky and Penton 1985; odonates, Van Buskirk 1988; salamanders, Fauth and Resitarits 1991), and interactions among predators from different phyla (odonates and salamanders, Travis et al. 1985; spiders and lizards, Schoener and Spiller 1987, Spiller and Schoener 1994; stoneflies and scul- 
pins, Soluk and Collins 1988, Soluk 1993; crabs and estuarine fish, Martin et al. 1989; salamanders, crayfish and trout, Resetarits 1991; herbivorous beetles and deer, Strauss 1991).

These studies have documented both additive (Travis et al. 1985, Van Buskirk 1988, Fauth and Resitarits 1991, Rice et al. 1993, Spiller and Schoener 1994) and nonadditive effects (Pecarsky and Penton 1985, Martin et al. 1989, Strauss 1991, Soluk 1993). Nonadditive effects can be positive or negative (Van Buskirk 1988): both interference among predators (leading to reduced effects on prey) and facilitation (leading to increased effects on prey) have been observed (Soluk 1993). These results suggest that trophic and behavioral responses between predators, between predators and prey, and/or interactions among prey could all be important.

One common response of prey fish is to shift habitats in the presence of predators. When the predators are other fish, this move often involves shifts to shallow water or other refuges, including submersed macrophytes (Crowder and Cooper 1982, Savino and Stein 1982, Cerri and Fraser 1983, Werner et al. 1983, Power et al. 1985, Power 1987, Crowder et al. 1994) or toward the surface (Safina and Burger 1989). When the predators are terrestrial, this shift is often to deeper water (Power 1984, 1987, Safina and Burger 1988). Predation by birds in shallow systems can be severe (Kushlan 1976). Although wading birds usually feed alone and for short periods, their energetic requirements are high (Kushlan 1978, 1981). However, predation by wading birds is limited by leg length (Whitfield and Blaber 1979), and their foraging effectiveness is reduced in water depths $>20 \mathrm{~cm}$ (Power 1987).

Although the behavioral responses of prey fish to aquatic and terrestrial predators are well-documented, we know of no experimental examples in which the combined effects of fish and bird predators on prey fish has been examined. Because prey fish generally move to shallow water to avoid swimming predators, that behavior could increase their risk of predation to terrestrial (i.e., wading bird) predators. Similarly, fish threatened by birds often seek to move into deeper water, which could increase their risk of predation by larger fish. We hypothesized that small prey fish $(<100$ $\mathrm{mm}$ total length) exposed to both fish and bird predators would experience nonadditive effects on their survival and size structure. Specifically, because they are sandwiched between terrestrial and aquatic predators, we expected their survival would be severely reduced due to the elimination of any depth refuge from predation.

In this paper, we present a test of our hypothesis using southern flounder (Paralichthys lethostigma) and wading birds as predators on a common estuarine fish, spot (Leiostomus xanthurus). In previous experiments on interactions among estuarine fish in North Carolina, we have documented that southern flounder have significant effects on spot survival and size (Rice et al.
1993, Wright et al. 1993). Based on diets of spot relative to benthic prey distributions, we inferred that spot shift to shallow water in the presence of flounder, but stay deep in their absence (Crowder et al. 1994), as one might expect based on other prey fish responses to piscivory. Many species of wading birds are permanent residents near Beaufort/Morehead City, North Carolina and feed exclusively on small fishes (Custer and Osborn 1978, Peterson and Peterson 1979, Fussell 1994). Nesting coincides with periods (April-May) when high numbers of small fish such as mummichog (Fundulus heteroclitus) and juvenile spot are found in marsh habitats (Potter et al. 1980, Hettler 1989). Nesting declines in late May, but provisioning of young continues through June and into July (Potter et al. 1980, Fussell 1994), so foraging by birds was likely to be intense during the period of our experiment. We had noted birds visiting our experimental ponds before, but this experiment constitutes the first evaluation of their effect on a known prey fish population.

\section{METHODS}

The experiments were conducted in two earthen ponds $\left(316 \mathrm{~m}^{2}\right)$ located at the University of North Carolina Institute of Marine Sciences, Morehead City, North Carolina. The ponds were $\approx 40 \mathrm{~cm}$ deep in the center and had a bottom substrate of fine-grained marsh mud and sand. This depth was chosen so that about half of the area in each pond section was $<20 \mathrm{~cm}$ deep and half was $>20 \mathrm{~cm}$ deep ( $20 \mathrm{~cm}$ is as about as deep as the largest wading birds can forage effectively). Each pond was subdivided into four $79 \mathrm{~m}^{2}$ sections with $6 \mathrm{~mm}$ mesh plastic fencing buried $0.2 \mathrm{~m}$ into the substrate. Water from adjacent Bogue Sound (a salinity of 25-31 [Practical Salinity Scale], $25-28^{\circ} \mathrm{C}$ ) was pumped into each pond at about $15 \mathrm{~L} / \mathrm{min}$, adequate to completely exchange the pond volume every 8-10 d, and drained through a center standpipe. Fencing was completed and water was flowing into the pond $1 \mathrm{mo}$ before the first experiment began. A wide variety of benthic fauna rapidly colonized the ponds via the water supply (Martin et al. 1989, Crowder et al. 1994).

The experiment was a $2 \times 2$ randomized complete block design with and without flounders and with and without bird exclosures $(2.5 \mathrm{~cm}$ bird netting covering the appropriate sections) as treatments. The experiment was replicated in two ponds (pond $=$ block) in June and again in July 1993 (time = block). Each experiment lasted $15 \mathrm{~d}$, to balance the potentially rapid effects of birds on spot mortality with the potentially slower impact of flounder (Rice et al. 1993, Wright et al. 1993). Ponds were drained for $7 \mathrm{~d}$ between the two experimental periods to minimize residual effects, and treatments were randomly assigned to pond sections for each time period. The prey fish, juvenile spot, were collected by seining near Beaufort, North Carolina during April and May, held in large flow-through seawater tanks at the National Marine Fisheries Service (NMFS) 
Laboratory in Beaufort, and fed commercial fish food. A random subsample of spot was taken to determine their initial size distribution (total length, TL, in millimeters), and 395 individuals were randomly assigned to each pond section ( 5 individuals $/ \mathrm{m}^{2}$ ). Five $\mathrm{spot} / \mathrm{m}^{2}$ is a reasonable density based on throw trap samples collected in the estuary (J. A. Rice and L. B. Crowder, unpublished data). These included densities up to $64 / \mathrm{m}^{2}$, but the geometric mean density was only $2-3 /$ $\mathrm{m}^{2}$ ). In June, initial spot lengths were 28-66 mm TL (mean $45 \mathrm{~mm}$ ); in July their initial lengths were 38 $93 \mathrm{~mm}$ TL (mean $60 \mathrm{~mm}$ ).

With the cooperation of a commercial pound net fisherman, southern flounder were collected in May, held in flow-through seawater tanks at the National Marine Fisheries Service, Beaufort Laboratory, and fed small spot and striped mullet Mugil cephalus. Flounder were individually measured (TL in millimeters) and weighed (wet mass in grams). Six individuals were randomly assigned to each treatment. This is about one flounder/13 $\mathrm{m}^{2}$, which is only slightly higher than field flounder densities (Wright et al. 1993). Stocking of both flounder and spot was conducted early in the morning to reduce mortality due to handling. In June, flounders initially were 181-217 mm TL (mean $201 \mathrm{~mm}$ ) and weighed 59.4-116.7 g wet mass (mean $85.0 \mathrm{~g}$ ); in July, flounders were 198-240 mm TL (mean $217 \mathrm{~mm}$ ) and weighed 77.3-140.1 g wet mass (mean $103.4 \mathrm{~g}$ ).

Birds were attracted to the experimental site by stocking a third pond (maximum depth $<20 \mathrm{~cm}$ ) with high densities of juvenile estuarine fish $\left(>10 / \mathrm{m}^{2}\right)$. This pond was repeatedly restocked over a 1 mo-period before the experiments began to attract birds to the site. At the beginning of each experiment, this pond was drained and birds which had been attracted to the shallow pond shifted to our experimental ponds over the next few days.

We monitored daylight bird visits to the ponds using time-lapse videotape recordings. All four sections of each pond were monitored throughout the daylight period by a video camera. Scenes were recorded for one six-second interval during each minute. Videotapes were later reviewed to document the number of visits by birds to each pond section. For each visit, bird species and duration of stay (to the nearest minute) were recorded. We were unable to observe any visits by birds to the ponds at night, although some local wading birds (e.g., Black-crowned Night Herons, Nycticorax nycticorax) do forage at night. We never noted any night heron tracks in the ponds nor did we observe any birds during occasional night visits to the ponds.

After the peak period of bird visits in the early morning (about 0800), we walked around the perimeter of each pond noting (on audiotape) bird footprints or tracks and recording numbers of small spot observed in the shallow $(<20 \mathrm{~cm})$ part of each pond section. Turbidity in the ponds was not recorded, but we could easily see the bottom of the pond well out past $20 \mathrm{~cm}$ depth. Although turbidity is highly variable in the field, water clarity in our ponds was not atypical for field conditions. These observations were made intermittently in the first experiment (June) and routinely in July. When we observed spot in the shallow part of each pond section, we noted their numbers, degree of aggregation, and any behaviors observed. Spot in particular treatments were sometimes seen in rather tight aggregations (10 or more individuals in a tight cluster, usually within one body length of each other, sometimes moving together as if schooling). Other spot were observed in groups of two or three, foraging individually; we called these loosely aggregated. Occasionally we saw both patterns in the same pond sector; we scored these as "mixed" in terms of aggregation. Once a week, in the afternoon (1500-1700) we recorded pond temperatures and salinities near the pond center; otherwise the ponds were left undisturbed so as not to frighten potential avian predators.

At the end of the experiment, the ponds were partially drained and repeatedly seined to recover surviving spot and flounder. After seining, the pond was drained completely and any remaining fish collected by hand. All spot and southern flounder were counted and measured to the nearest millimeter TL; flounders were also weighed to determine their mass. The effects of flounder and birds on spot survival and growth were analyzed using $2 \times 2$ ANOVA with blocking for pond and time. ANCOVA was also conducted on the spot survival data using bird-minutes as a covariate. Our hypothesis that multiple predators would produce nonadditive spot mortality rates was tested by comparing spot survival rate in the bird $\times$ flounder treatment with that expected if risks due to the separate predators were independent (i.e., if the survival rates due to birds and due to flounders were added, Van Buskirk 1988). We also calculated instantaneous daily mortality rates (based on an exponential mortality rate model, Cushing 1981) for each treatment in order to make qualitative comparisons among treatments and with field estimates of mortality rates. Flounder growth (the percentage of growth in length and mass) was also analyzed by ANOVA to examine bird effects as well as pond and time blocking factors. The number of spot seen in shallow water $(<20 \mathrm{~cm})$ in each treatment was also analyzed using $2 \times 2$ ANOVA. We tested for differences in the pattern of spot aggregation among treatments using a Kolomogorov-Smirnov test on pooled observations from all replicates. In all cases, $P<0.05$ was considered significant.

\section{RESULTS}

All flounder stocked in these experiments survived and grew during the trials. There were no significant effects of birds on the percentage of growth of flounder in either length $(F=0.03$, df $=1,4, P>0.86)$ or mass $(F=3.75$, df $=1,4, P>0.12)$. Neither were there significant blocking effects due to the ponds $(P$ 


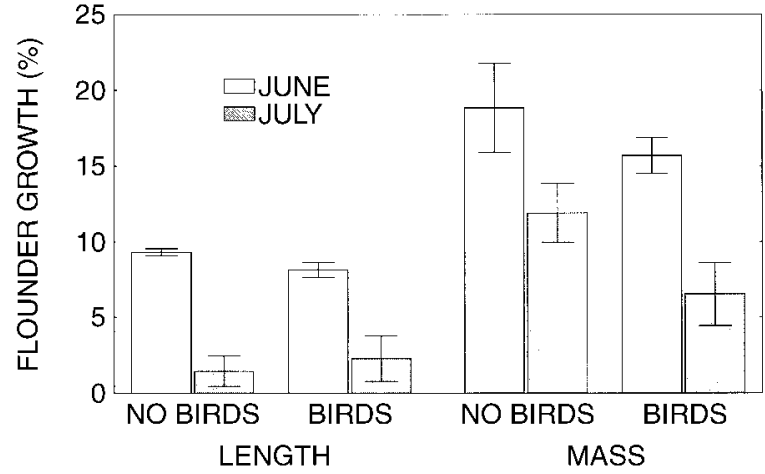

FIG. 1. Percentage growth rates of southern flounder (Paralichthys lethostigma) in total length and in mass (mean \pm 1 $\mathrm{SE}, r$ [number of replicates] $=4$ ) in experimental pond sections $\left(79 \mathrm{~m}^{2}\right)$ with bird access and no birds. The 15-d experiments contained spot (Leiostomus xanthurus) as prey and were conducted in early June (open bars) and again in early July (shaded bars).

$>0.40, P>0.99$, for the percentages of length and mass, respectively), but flounder grew more slowly in July than in June (percentage of length $-F=50.36$, df $=1,4, P<0.003$, percentage of mass $-F=13.44$, df $=1,4, P<0.03$, Fig. 1).

Our experiments were visited relatively infrequently by birds. Over both experimental periods ( $30 \mathrm{~d}$ total), we identified seven species of birds visiting our ponds in 251 recorded visits (Table 1). There was no obvious difference in the total number of bird visits between flounder and no flounder treatments (133 in flounder sections vs. 118 in no flounder sections). Birds visited the pond sections relatively infrequently (mean 4.2 visits/d) and for relatively short durations (1-22 min, mean $2.0 \mathrm{~min}$ ). Wading birds (egrets and herons, Table 1) accounted for only $25 \%$ of the total visits, but tended to stay in the ponds longer (mean duration $4.4 \mathrm{~min}$ ). Overall, bird visit rates peaked on Day 5 and declined as spot were depleted in the ponds (Fig. 2). A similar pattern occurred in each of the pond sections with bird
TABLE 1. Bird species observed visiting our experimental ponds. A total of 251 daylight visits were recorded on timelapse video.

\begin{tabular}{llrr}
\hline \hline \multicolumn{1}{c}{ Common name } & Scientific name & \multicolumn{2}{c}{$\begin{array}{c}\text { Num- Percent- } \\
\text { ber }\end{array}$} \\
age \\
\hline Great Egret & Casmerodius albus & 60 & 23.9 \\
Reddish Egret $\dagger$ & Egretta rufescens & 1 & 0.4 \\
Green-backed Heron & Butorides striatus & 1 & 0.4 \\
Laughing Gull & Larus atricilla & 8 & 3.2 \\
Boat-tailed Grackle & Quiscalus major & 163 & 64.9 \\
Clapper Rail & Rallus longirostris & 2 & 0.8 \\
Spotted Sandpiper & Actitis macularia & 4 & 1.6 \\
Unidentified & & 12 & 4.8 \\
\hline
\end{tabular}

$\dagger$ Reddish egrets are rare in North Carolina, but this identification was confirmed by John Fussel. Others confirmed citing a Reddish Egret in the vicinity of our experiments.

access (six out of eight peaked on Day 5 and declined, another peaked on Day 6, and the last peaked on Day 2 ). Although visit rates were highly variable, visits per day for all birds averaged $2.7 \times$ higher in June than in July. The pattern was reversed for wading birds-visitation rates were $4.2 \times$ higher in July than in June. At no time were any birds observed in any of the bird exclosures, although one Great Egret was observed bouncing off the bird netting while attempting to land in one exclosure.

In June, afternoon pond temperatures averaged 30$31^{\circ} \mathrm{C}$ near the surface, and salinity averaged $27-30 \mathrm{psu}$. There was no evidence of pond stratification. In July, the ponds were hotter, averaging $34-35^{\circ} \mathrm{C}$, and salinity averaged 29-30 psu. A min-max thermometer deployed in mid-July documented a diel change in temperature near the pond surface of $7-10^{\circ} \mathrm{C}$. Although these temperatures we slightly higher than average estuarine temperatures occupied by these fish, they are not unusual for isolated tidal pools.

Spot survival was significantly reduced by flounder $(F=151.88$, df $=1,10, P=0.0001)$, but not significantly affected by bird predation $(F=0.63, \mathrm{df}=1$, $10, P=0.44$, Fig. 3 ). There was a significant flounder $\times$ bird interaction on spot survival $(F=7.67$, df $=1$,

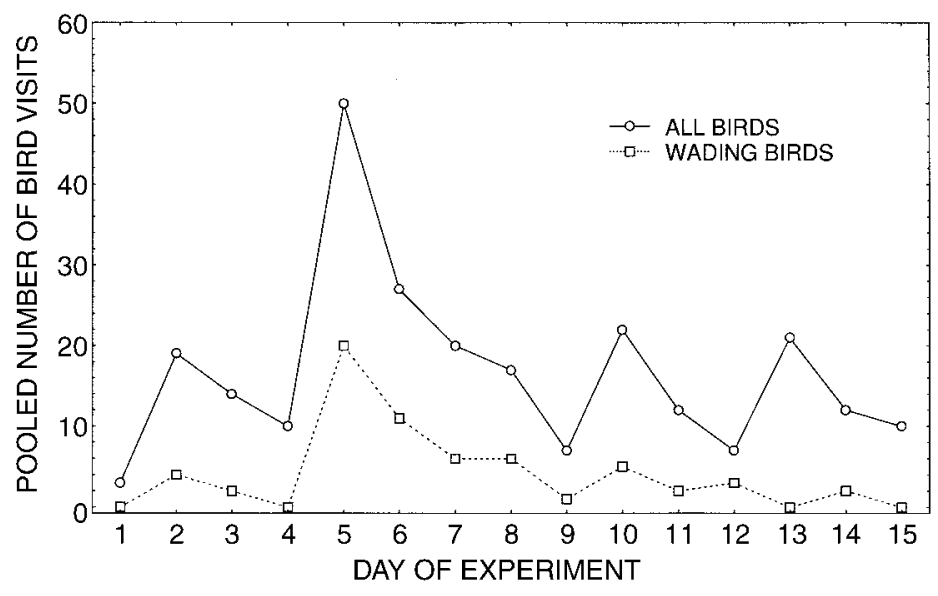

FIG. 2. Total number of bird visits to experimental pond sections with bird access during 15-d experimental trials in June and July. Patterns in specific pond sections were qualitatively similar. All daylight visits were recorded using time-lapse video which recorded one six-second interval during each minute. All birds observed are shown by the solid line; wading birds (Table 1) are shown with the dotted line. 


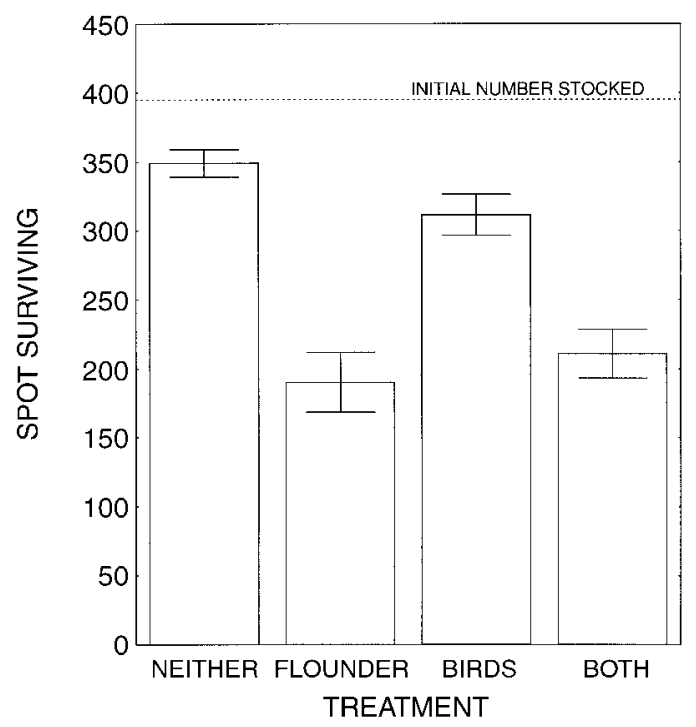

FIG. 3. Number of spot surviving (mean $= \pm 1 \mathrm{SE}, r$ [number of replicates] $=4$ ) in a $2 \times 2$ factorial experiment with southern flounder and birds as predators. The experimental replicates were conducted in early June and again in early July each for a duration of $15 \mathrm{~d}$.

$10, P=0.0198)$. Analysis of covariance on spot survival, which treated bird-minutes in each pond section as a covariate, provided similar results: the direct effect of birds was still insignificant $(P>0.20)$. Spot survival in the controls averaged $88 \%$ for the $15 \mathrm{~d}$ experiments; with birds survival averaged $78 \%$. Spot survival with flounder alone averaged $48 \%$, but spot survival with both flounder and birds averaged 53\%. Birds alone reduced spot densities by an average of 38 fish relative to the controls; flounder alone reduced spot by 159 individuals. Together, birds and flounder removed only 138 spot-about $70 \%$ of the number expected based on the sum of bird and flounder effects (197 spot). Assuming that the effects of the separate predators on spot survival rate are independent (Van Buskirk 1988), expected survival in the bird $\times$ flounder treatment was $43 \%$, but spot survival was 1.2 times better (53\% of spot) with both predators than one would expect from their additive effects.

Estimates of instantaneous daily mortality rates for spot ranged from $0.8 \% / \mathrm{d}$ in the controls to $4.9 \%$ /d with flounder over both experimental periods (Table 2). These rates are comparable to those observed in the

TABLE 2. Estimated per capita instantaneous daily mortality rate of juvenile spot from the combined treatments.

\begin{tabular}{lc}
\hline \hline \multicolumn{1}{c}{ Treatment } & $\begin{array}{c}\text { Mortality rate } \\
\left(\mathrm{d}^{-1}\right)\end{array}$ \\
\hline Neither flounder nor birds & -0.008 \\
Flounder & -0.049 \\
Birds & -0.016 \\
Both flounder and birds & -0.042 \\
Expected additive effect & -0.064 \\
\hline
\end{tabular}

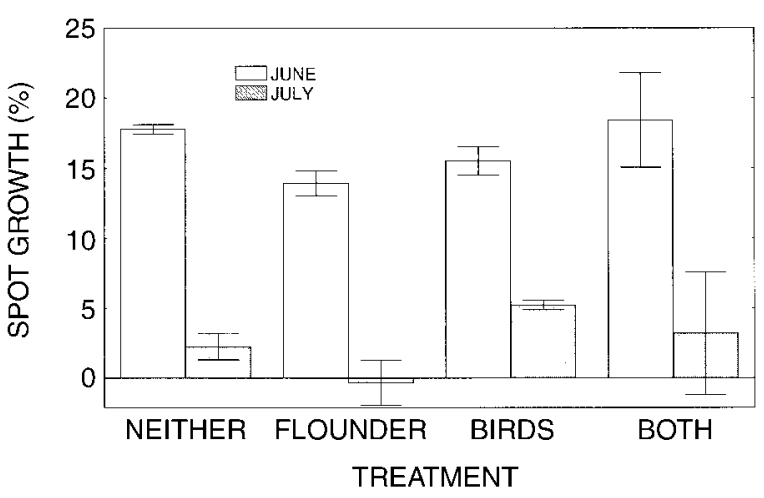

FIG. 4. Spot growth (the percentage of total length) in a $2 \times 2$ factorial experiment with southern flounder and birds as predators (mean $\pm 1 \mathrm{SE}$ ). The experimental replicates were conducted in early June (open bars) and again in early July (shaded bars). Experiments lasted $15 \mathrm{~d}$.

field (Wright et al. 1993). Mortality rates observed in the flounder $\times$ bird treatment were also nonadditive. Expected daily mortality rates based on additive effects were 1.5 times higher than observed rates (Table 2). Spot experienced lower mortality with both predators than one would have expected based on the separate effects of each predator. Growth rates of spot were unaffected by treatment (flounder $P=0.36$, birds $P=$ 0.16 , flounder $\times$ birds $P=0.32$ ), but spot, as did the flounders, grew more poorly in July than in June $(F=$ 52.66 , df $=1,10, P<0.0001$, Fig. 4). Growth in total length averaged $14-18 \%$ in June, but only $0-5 \%$ in July. The standard deviation of growth rates in spot significantly increased with predation by flounder $(F$ $=26.57, \mathrm{df}=1,3, P<0.02)$ and birds $(F=12.81$, $\mathrm{df}=1,3, P<0.04)$. The bird $\times$ flounder interaction was also significant $(F=12.16$, df $=1,3, P<0.04)$.

Significantly more spot were observed in shallow water $(<20 \mathrm{~cm})$ with flounder $(F=19.84$, df $=1,202$, $P<0.0001$, Fig. 5). Birds did not affect the number

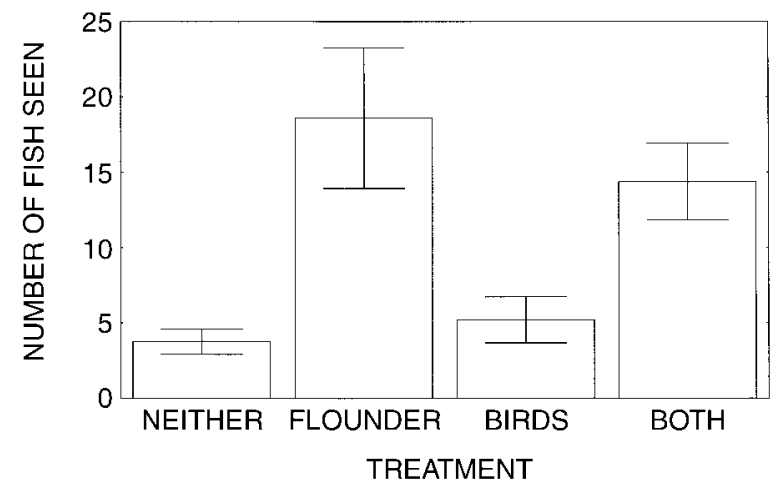

FIG. 5. Number of fish observed in shallow water (depth $<20 \mathrm{~cm}$ ) by treatment (mean $\pm 1 \mathrm{SE}$ ). Observations were recorded on audiotape while walking around the perimeter of the ponds after the morning peak of bird visitation (about 0800). Data are pooled for June and July. 

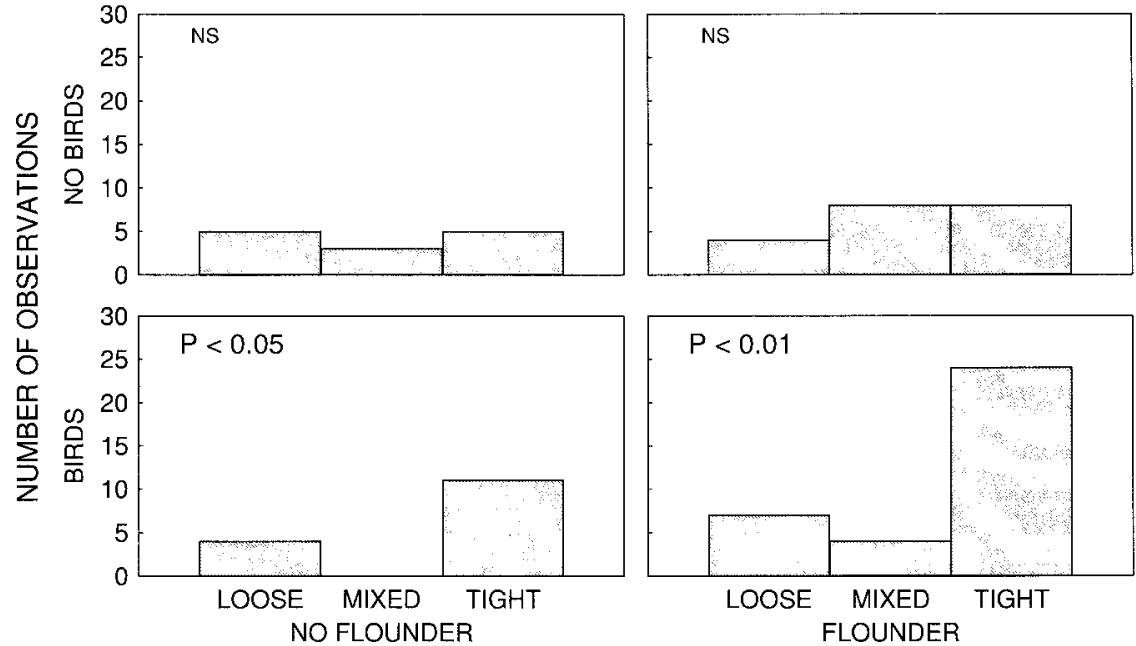

SPOT AGGREGATION

FIG. 6. Degree of aggregation in spot observed in shallow water (depth $<20 \mathrm{~cm}$ ) by treatment. Observations were recorded on audiotape while walking around the perimeter of the ponds after the morning peak of bird visitation (about 0800). Data were pooled for June and July. $P$ values represent significant differences in aggregation behavior as determined by a Kolmogorov-Smirnov test.

observed $(P=0.44)$, nor was there an interaction effect $(P=0.48)$. On average, about 4 times more spot were seen in sections with flounder than without (Fig. 5). Spot in shallow water were also significantly more aggregated in the presence of birds than in their absence (Kolmogorov-Smirnov test, $P<0.05$, Fig. 6); there was no distinct aggregation response in the flounder treatment or the control. We also noted that fish in the bird access treatments tended to exhibit more behaviors we associated with predator evasion, including a rapid, frenetic, zig-zag response to observers approaching from shore. Fish in the no-bird treatments appeared calmer and did not respond strongly to the approach of observers. We noted this frenetic response by spot in $34 \%$ of our observations in sections with birds and flounders, and in $19 \%$ of our observations in birds alone sections. Treatments with flounders and no predators averaged $6 \%$ and $4 \%$ respectively.

\section{Discussion}

We predicted that flounder and birds would have a significant nonadditive effect on spot survival. Further, we predicted that this effect would be negative (i.e., it would reflect facilitation between predators) because all depth refuges were eliminated. We documented a strong direct effect of flounder on spot survival as we had before (Rice et al. 1993, Wright et al. 1993, Crowder et al. 1994), but the bird effect was variable and not significant. We did not enclose avian predators, and depended upon birds to visit at will. We had a reasonable number of total bird visits, but the number of visits by wading birds, which are likely to represent the greatest predation risk, was limited, highly variable, and their duration was short. Still, the birds generated a substantial reduction in survival relative to controls: our inability to detect a direct effect of birds on spot survival was probably limited by the modest total time birds visited the ponds and by variation among treatments in bird visits. We did detect a significant bird $\times$ flounder interaction on spot survival, which provides statistical evidence for a potentially important biological interaction, although again the magnitude of the effect was modest.

The effect of flounder and birds on spot survival was nonadditive; spot survived better in the presence of both predators than one would predict based on the separate, additive effects of the predators. This result was contrary to our prediction-spot had no depth refuge, yet they survived better with both predators.

The conventional explanations for increased prey survival in the presence of multiple predators is interference (Van Buskirk 1988, Soluk 1993); or that one of the two predators is really an intermediate predator, also vulnerable to predation by the top predator (Polis et al. 1989, Polis 1991, Spiller and Schoener 1994). Birds and flounders may have interfered with each other, reducing predation on spot. However, we know of no evidence that flounders interfere with birds, and we have no evidence from this experiment that birds avoided flounder sections. Perhaps flounder perceive birds as a threat, causing them to reduce their foraging activity.

Several lines of evidence cause us to doubt this explanation. First, few of the birds which visited our ponds could consume a flounder $200+\mathrm{mm}$ long, although they could damage such a flounder. Second, all flounder in our treatments survived, so at best the effects of birds on flounders were sublethal. Finally, there 
was no significant effect of birds on flounder growth rate, providing no support for the idea of sublethal effects.

A second explanation for the observed nonadditive effect hinges on spot behavioral responses to flounder and birds. We were able to document, via direct observation, that spot move to shallow water in the presence of flounder. We had deduced this behavior from previous experiments based on spot diets with and without flounder (Crowder et al. 1994), but we had not made direct observations previously. We assume this shift acts to reduce mortality due to flounder. We also documented that spot tend to aggregate and show stronger predator-avoidance behaviors in the bird treatments. This behavior may operate to reduce risk of predation to birds. It could also reduce encounters with flounder, generating the nonadditive effect. Because little evidence is available to support the interference hypothesis, we tend to favor the spot behavioral response hypothesis.

We detected no significant effect of treatments on spot size at the end of the experiment, but spot growth rates appeared more variable with predators. This pattern could reflect variance in individual behavioral strategies in response to predators. Both flounder and spot grew poorly in July relative to June; we attribute this to the extreme temperatures in these shallow ponds in July. We know flounder consumed similar numbers of (larger) spot in July as in June, but they grew at only one-fourth to one-third the rate. Optimal temperature for growth for juvenile flounder is $31^{\circ} \mathrm{C}$ (Peters 1971). Pond temperatures reached $34-35^{\circ} \mathrm{C}$ in July, but were near optimal temperatures for growth in June.

Previous studies of predation on fish have focused on terrestrial (Kushlan 1976, Power 1984) or aquatic predators (Werner et al. 1983, Power et al. 1985, Rice et al. 1993, Wright et al. 1993), but not both. This paper constitutes the first example that experimentally documents significant interactions between terrestrial and aquatic predators. This interaction is not uncommon. For example, small pelagic fishes driven to the surface by aquatic predators are often preyed upon by aggregations of seabirds. Safina (1990, Safina and Burger 1988, 1989) noted that bluefish (Pomatomus salatrix) mediate the competition interaction between Roseate and Common Terns (Sterna dougallii, S. hirundo). Roseate Terns fish more successfully than Common Terns in the absence of bluefish, and the outcome is reversed if bluefish are present. The interaction has to do with bluefish driving prey nearer the surface and with alterations of bird predator and prey fish behavior. Commercial and recreational fishermen often locate schools of fish by noting seabird aggregations (Manooch and Raver 1984).

Our experiment documents a nonadditive interaction between terrestrial and aquatic predators on spot. We now know that we cannot expect to explain the effects of this multispecies predator assemblage on their prey by combining information obtained from single predator experiments. Most of the current studies of predator effects on prey communities consider only a single type of predator, but most prey face multiple predators. Predator and prey behaviors enrich the possible direct and indirect interactions that can influence prey communities (Kerfoot and Sih 1987, Wooten 1994). Increasing evidence suggests that nonadditive effects are common, and suggests that additional experimental research will be required before the dynamics of multispecies systems can be adequately modeled or managed (Van Buskirk 1988).

\section{ACKNOWLEDGMENTS}

We thank Jeff Walters, Jaime Collazo, Carole McIvor, Mary Power, and an anonymous reviewer for providing comments on a previous version of the manuscript. We also thank Braxton Tesh and the support staff of the Institute of Marine Sciences, University of North Carolina. Bill Hettler kindly provided tank space at the Beaufort Laboratory, National Marine Fisheries Service. We also acknowledge the field assistance of Maurice Crawford, Lynn Heatherly, Shawna Little, Braden McCollum, David Nadeau, and Steve Nixon. Jeffery Priddy assisted with data analysis and graphics. This research was supported by the National Sea Grant College Program, National Oceanic and Atmospheric Administration, and the University of North Carolina Sea Grant Program under grant NA90AA-D-SG062 (R/MER-24) and the NOAA Coastal Ocean Program Project NA16RG0492-01 (R/SAB-4). The views expressed herein are those of the authors and do not necessarily reflect the views of the National Oceanic and Atmospheric Administration or any of its subagencies.

\section{Literature Cited}

Abrams, P. 1987. Indirect interactions between species that share a predator: varieties of indirect effects. Pages 38-54 in W. C. Kerfoot and A. Sih, editors. Predation: direct and indirect impacts on aquatic communities. University Press of New England, Hanover, New Hampshire, USA.

Addicott, J. F. 1974. Predation and prey community structure: an experimental study of the effect of mosquito larvae on the protozoan community of pitcher plants. Ecology 55: 465-492.

Brooks, J. L., and S. I. Dodson. 1965. Predation, body size, and the composition of zooplankton. Science 150:28-35.

Carpenter, S. R., J. F. Kitchell, and J. R. Hodgson. 1985. Cascading trophic interactions and lake productivity. BioScience 35:634-639.

Carpenter, S. R., J. F. Kitchell, J. R. Hodgson, P. A. Cochran, J. J. Elser, M. M. Elser, D. M. Lodge, D. Kretchmer, X. He, and C. N. von Ende. 1987. Regulation of lake primary productivity by food web structure. Ecology 68:18631876.

Cerri, R. D., and D. F. Fraser. 1983. Predation and risk in foraging minnows: balancing conflicting demands. American Naturalist 121:552-561.

Crowder, L. B., and W. E. Cooper. 1982. Habitat structural complexity and the interaction between bluegills and their prey. Ecology 63:1802-1813.

Crowder, L. B., R. A. Wright, K. A. Rose, T. H. Martin, and J. A. Rice. 1994. Direct and indirect effects of southern flounder predation on a spot population: experimental and model analyses. Pages 61-77 in D. J. Stouder, K. L. Fresh, and R. J. Feller, editors. Theory and application in fish feeding ecology. University of South Carolina Press, Columbia, South Carolina, USA.

Cushing, D. H. 1981. Fisheries biology: a study in population 
dynamics. University of Wisconsin Press, Madison, Wisconsin, USA.

Custer, T. W., and R. G. Osborn. 1978. Feeding habitat use by colonially-breeding herons, egrets and ibises in North Carolina. Auk 95:733-743.

Dodson, S. I. 1974. Zooplankton competition and predation: an experimental test of the size-efficiency hypothesis. Ecology 55:605-613.

Fauth, J. E., and W. J. Resetarits, Jr. 1991. Interactions between the salamander Siren intermedia and the keystone predator Notopthalmus viridescens. Ecology 72:827-838.

Fussell, J. O. III. 1994. A birder's guide to coastal North Carolina. University of North Carolina Press, Chapel Hill, North Carolina, USA.

Hettler, W. F. 1989. Nekton use of regularly flooded saltmarsh cordgrass habitat in North Carolina, USA. Marine Ecology Progress Series 56:111-118.

Holt, R. D. 1977. Predation, apparent competition, and the structure of prey communities. Theoretical Population Biology 12:197-229.

Hurlburt, S. H., J. Zedler, and D. Fairbanks. 1972. Ecosystem alteration by mosquitofish (Gambusia) predation. Science 175:639-641.

Kerfoot, W. C., and A. Sih. 1987. Predation: direct and indirect impacts on aquatic communities. University Press of New England, Hanover, New Hampshire, USA.

Kushlan, J. A. 1976. Wading bird predation in a seasonally fluctuating pond. Auk 93:464-476.

. 1978. Feeding ecology of wading birds. Pages 249297 in A. Sprunt IV, J. C. Ogden, and S. Winckler, editors. Wading birds. National Audubon Society, Research Report 7, New York, New York, USA

- 1981. Resource use strategies of wading birds. Wilson Bulletin 93:145-163.

Levine, S. H. 1976. Competitive interactions in ecosystems. American Naturalist 110:903-910.

Manooch, C. S., and D. Raver. 1984. Fishes of the southeastern United States. North Carolina Museum of Natural History, Raleigh, North Carolina.

Martin, T. H., R. A. Wright, and L. B. Crowder. 1989. Non additive impact of blue crabs and spot on their prey assemblages. Ecology 70:1935-1942.

Morin, P. J. 1983. Predation, competition, and the composition of larval anuran guilds. Ecological Monographs $\mathbf{5 3}$ 119-138.

Paine, R. T. 1966. Food web complexity and species diversity. American Naturalist 100:65-75.

Peckarsky, B. L. 1980. Predator-prey interactions between stoneflies and mayflies: behavioral observations. Ecology 61:932-943.

Peckarsky, B. L., and S. I. Dodson. 1980. Do stonefly predators influence benthic distributions in streams? Ecology 61: $1275-1282$

Peckarsky, B. L., and M. A. Penton. 1985. Is predacious stonefly behavior affected by competition? Ecology 66 $1718-1728$.

Peters, D. S. 1971. Growth and energy utilization of juvenile flounder, Paralichthys dentatus, and Paralichthys lethostig$m a$, as affected by temperature, salinity and food availability. Dissertation, North Carolina State University, Raleigh, North Carolina, USA.

Peterson, C. H., and N. M. Peterson. 1979. The ecology of intertidal flats in North Carolina: a community profile. U.S Fish and Wildlife Service, Office of Biological Services. FWS/OBS-79/39.

Polis, G. A. 1991. Complex trophic interactions in deserts: an empirical critique of food web theory. American Naturalist 138:123-155.

Polis, G. A., C. A. Myers, and R. D. Holt. 1989. The ecology and evolution of intraguild predation: potential competitors that eat each other. Annual Review of Ecology and Systematics 20:297-330.

Potter, E. F., J. F. Parnell, and R. P. Teulings. 1980. Birds of the Carolinas. University of North Carolina Press, Chapel Hill, North Carolina, USA.

Power, M. E. 1984. Depth distributions of armored catfish: predator-induced resource avoidance? Ecology 65:523528.

- 1987. Predator avoidance by grazing fishes in temperate and tropical streams: importance of stream depth and prey size. Pages 333-351 in W. C. Kerfoot and A. Sih, editors. Predation: direct and indirect impacts on aquatic communities. University Press of New England, Hanover, New Hampshire, USA.

1990. Effects of fish in river food webs. Science 250:811-814.

Power, M. E., W. J. Matthews, and A. J. Stewart. 1985. Grazing minnows, piscivorous bass and stream algae: dynamics of a strong interaction. Ecology 66:1148-1456.

Resetarits, W. J., Jr. 1991. Ecological interactions among predators in experimental stream communities. Ecology 72: $1782-1793$.

Rice, J. A., L. B. Crowder, and K. A. Rose. 1993. Interactions between size-structured predator and prey populations: experimental test and model comparison. Transactions of the American Fisheries Society 122:481-491

Safina, C. 1990. Bluefish mediation of foraging competition between Roseate and Common Terns. Ecology 71:18041809.

Safina, C., and J. Burger. 1988. Ecological dynamics among prey fish, bluefish and foraging Common Terns in an Atlantic coastal system. Pages 95-173 in J. Burger, editor. Seabirds and other marine vertebrates: competition, predation and other interactions. Columbia University Press, New York, New York, USA.

Safina, C., and J. Burger. 1989. Population interactions among free-living bluefish and prey fish in an ocean environment. Oecologia 79:91-95.

Savino, J., and R. A. Stein. 1982. Predator-prey interaction between largemouth bass and bluegills as influenced by simulated, submersed vegetation. Transactions of the American Fisheries Society 111:255-266.

Sih, A. 1982. Foraging strategies and avoidance of predation by an aquatic insect, Notonecta hoffmanni. Ecology 63: 786-796.

- 1987. Predators and prey lifestyles: an evolutionary and ecological overview. Pages 203-224 in W. C. Kerfoot and A. Sih, editors. Predation: direct and indirect impacts on aquatic communities. University Press of New England, Hanover, New Hampshire, USA.

Sih, A., P. H. Crowley, M. A. McPeek, J. W. Petranka, and K. Strohmeier. 1985. Predation, competition, and prey communities: a review of field experiments. Annual Review of Ecology and Systematics 16:269-312.

Schoener, T. W., and D. A. Spiller. 1987. Effects of lizards on spider populations: manipulative reconstruction of a natural experiment. Science 236:949-952.

Soluk, D. A. 1993. Multiple predator effects: predicting combined functional response of stream fish and invertebrate predators. Ecology 74:219-225.

Soluk, D. A., and N. C. Collins. 1988. Synergistic interactions between fish and invertebrate predators: facilitation and interference among stream predators. Oikos 52:94100.

Spiller, D. A., and T. W. Schoener. 1994. Effects of top and intermediate predators in a terrestrial food web. Ecology 75:182-196.

Stein, R. A., and J. J. Magnuson. 1976. Behavioral response of crayfish to a fish predator. Ecology 58:571-581.

Strauss, S. Y. 1991. Direct, indirect and cumulative effects 
of three native herbivores on a shared host plant. Ecology 72:543-558.

Travis, J., W. H. Keen, and J. Julianna. 1985. The effects of multiple factors on viability selection in Hyla gratiosa tadpoles. Evolution 39:1087-1099.

Van Buskirk, J. 1988. Interactive effects of dragonfly predation in experimental pond communities. Ecology 69: 857-867.

Werner, E. E., J. F. Gilliam, D. J. Hall, and G. G. Mittelbach 1983. An experimental test of the effects of predation risk on habitat use in fish. Ecology 64:1540-1548.

Whitfield, A. K., and S. J. M. Blaber. 1979. Feeding ecology of piscivorous birds at Lake St. Lucia, Part 2: wading birds. Ostrich 50:1-9.
Wilbur, H. M. 1987. Regulation of structure in complex systems: experimental temporary pond communities. Ecology 68: $1437-1452$.

Wootton, J. T. 1993. Indirect effects and habitat use in an intertidal community: interaction chains and interactions modifications. American Naturalist 141:71-89.

1994. The nature and consequences of indirect effects in ecological communities. Annual Review of Ecology and Systematics 25:443-466.

Wright, R. W., L. B. Crowder, and T. H. Martin. 1993. The effects of predation on the survival and size distribution of estuarine fishes: an experimental approach. Environmental Biology of Fishes 36:291-300.

Zaret, T. M. 1980. Predation and freshwater communities. Yale University Press, New Haven, Connecticut, USA. 